\title{
Correction to: Multivariate statistical and trend analyses of surface water quality in the central Indian River Lagoon area, Florida
}

\author{
Sayem Zaman ${ }^{1,6} \cdot$ Ming Ye $^{2,3}$ (C) $\cdot$ Fan Zhang ${ }^{4} \cdot$ Mingming Zhu ${ }^{5}$
}

Published online: 28 February 2018

c) Springer-Verlag GmbH Germany, part of Springer Nature 2018

\section{Correction to: Environmental Earth Sciences (2018) 77:127 https://doi.org/10.1007/s12665-018-7266-0}

Unfortunately, the online version of the original article has an error in authors' names.

In the original article, the name of the first author was accidentally misspelled.

The correct names and affiliations of all authors are given below:

Sayem Zaman ${ }^{1,6} \cdot$ Ming Ye ${ }^{2,3} \cdot$ Fan Zhang ${ }^{4} \cdot$ Mingming $\mathrm{Zhu}^{5}$

Corresponding Author: Ming Ye, mye@fsu.edu

${ }^{1}$ Department of Scientific Computing, Florida State University, Tallahassee, FL, USA
${ }^{2}$ School of Computer Science and Software Engineering, Tianjin Polytechnic University, Tianjin 300387, China

${ }^{3}$ Department of Earth, Ocean, and Atmospheric Science, Florida State University, Tallahassee, FL, USA

${ }^{4}$ Key Laboratory of Tibetan Environmental Changes and Land Surface Processes, Institute of Tibetan Plateau Research, Chinese Academy of Sciences, Beijing 100101, China

${ }^{5}$ Center of Hydraulic Engineering Regulation and Management, Jinzhou Waterwork Office, Jinzhou 121013, Liaoning, China

${ }^{6}$ Present Address: Draper Aden Associates, Richmond, VA, USA

The original article can be found online at https://doi.org/10.1007/ s12665-018-7266-0.

\section{Ming Ye}

mye@fsu.edu

1 Department of Scientific Computing, Florida State University, Tallahassee, FL, USA

2 School of Computer Science and Software Engineering, Tianjin Polytechnic University, Tianjin 300387, China

3 Department of Earth, Ocean, and Atmospheric Science, Florida State University, Tallahassee, FL, USA

4 Key Laboratory of Tibetan Environmental Changes and Land Surface Processes, Institute of Tibetan Plateau Research, Chinese Academy of Sciences, Beijing 100101, China

5 Center of Hydraulic Engineering Regulation and Management, Jinzhou Waterwork Office, Jinzhou 121013, Liaoning, China

6 Present Address: Draper Aden Associates, Richmond, VA, USA 